九州大学学術情報リポジトリ

Kyushu University Institutional Repository

\title{
Preliminary Tests for Optically Measuring Drying Strains and Check Formation in Wood
}

\section{Kang, Ho-Yang}

Department of Biobased Materials, College of Agriculture and Life Sciences, Chungnam National University

\section{Muszynski}

Department of Wood Science and Engineering, College of Forestry, Oregon State University

Milota, Michael R.

Department of Wood Science and Engineering, College of Forestry, Oregon State University

Kang, Chun-Won

Department of Housing Environmental Design, and Research Institute of Human Ecology, College of Human Ecology, Chonbuk National University

他

https://doi.org/10.5109/20326

出版情報 : 九州大学大学院農学研究院紀要. 56 (2), pp.313-316, 2011-09. 九州大学大学院農学研究院 バージョン：

権利関係 : 


\title{
Preliminary Tests for Optically Measuring Drying Strains and Check Formation in Wood
}

\author{
Ho-Yang KANG ${ }^{1}$, Lech MUSZYNSKI ${ }^{2}$, Michael R. MILOTA ${ }^{3}$, \\ Chun-Won KANG ${ }^{4 *}$ and Junji MATSUMURA ${ }^{5}$
}

\author{
Laboratory of Wood Science, Department of Forest and Forest Product Science, \\ Faculty of Agriculture, Kyushu University, Fukuoka 812-8581, Japan \\ (Received April 28, 2011 and accepted May 9, 2011)
}

\begin{abstract}
This study deals with the visualization of deformation during wood drying by Digital Image Correlation method using an Optical Measurement System. By this measurement, localized deformation by drying stress can be observed in naked eye. Estimation of displacement maps of willow tree disks and Oregon oak planks provided the strain distribution during drying of wood. And the stress concentration in the Oregon oak plank was successfully visualized.

It is considered that the use of a DIC system in wood drying can more accurately visualize strain changes of wood surface and using of DIC may provide more appropriate drying schedule preparation for unknown species or refractory wood species.
\end{abstract}

Keywords: drying strain, check formation, optical measurement, DIC (digital image correlation) system

\section{INTRODUCTION}

Wood is a porous hygroscopic material whose moisture content changes with variations in the circumferential moisture conditions. These moisture changes can cause dimensional and physical property changes in wood. To assure the structural and physical stabilities of wood, its moisture content should be controlled through drying.

Wood shrinkage during the drying process causes deformation. This deformation originates in a localized position and is non-uniform. Wood scientists, therefore, have been interested in analyzing the wood deformation processes during drying. There are many models for predicting wood deformation and stress changes during drying (Ormarsson et al., 1999; Carlsson, 2001; Pang et al., 2001; Kang and Lee, 2002; Svensson and Martensson, 2002); however, these mathematical models have not been adequately confirmed through experiments.

Wood drying stress can be measured using various methods, such as a prong test, a slice test or a dissection test. However, these methods are destructive, discrete and retrospective. One non-destructive method is the sound radiation or acoustic emission method, which uses an $\mathrm{AE}$ transducer to detect the stress waves that occur

1 Department of Biobased Materials, College of Agriculture and Life Sciences, Chungnam National University, Daejeon 305764 , Korea

2 Department of Wood Science and Engineering, College of Forestry, Oregon State University, Corvallis, OR 97331, USA

3 Department of Wood Science and Engineering, College of Forestry, Oregon State University, Corvallis, OR 97331, USA

${ }^{4}$ Department of Housing Environmental Design, and Research Institute of Human Ecology, College of Human Ecology, Chonbuk National University, Jeonju 561-756, Korea

5 Laboratory of Wood Science, Division of Sustainable Bioresources Science, Department of Agro-environmental Sciences, Faculty of Agriculture, Kyushu University, Fukuoka 812-8581, Japan

* Corresponding author (E-mail: kcwon@jbnu.ac.kr) due to drying. This method is effective for continuous detection of local microscopic observations during wood drying, but it is not available for wide-ranging strain observation because the stress wave sounds originate in localized positions (Breese et al., 1995; Krug et al., 1995; Lee et al., 1995; Kim et al., 2005). In addition, shrinkage and microcrack of wood during drying were visualized in microscopic level by in-situ observation using CLSM (confocal laser scanning microscopy). (Sakagami et al., 2007; Sakagami et al., 2009a; Sakagami et al., 2009b)

Therefore, we hypothesized that an optical measurement technique which takes advantage of Digital Image Correlation (DIC) could visualize strain deformation during wood drying. DIC is usually performed by determining the maximum of the correlation between original and deformed images. The cross correlation coefficient is defined as pixel intensity or the gray scale value at original point and deformed image. In this study, applying paint to the surface of non-dried wood, two cameras track the wood surface movement resulted from speckle pattern changes by drying stress occurred by locally originated strain. This technology has been used since the late 1980s to investigate the displacement of material loaded under stress (Ranson et al., 1987; Bruck et al., 1989; Vendroux and Knauss, 1998). It has been used successfully to detect deformations in wood fiber, paper, wood and wood-based materials because it can measure deformations in material surfaces ranging in size from a micron to a meter (Sutton and Chao, 1988; Zink et al., 1995; Mott et al., 1996; Choi and Shah, 1997; Muszy'n ski et al., 2006; Sinha et al., 2006). Concerning the relationship between wood deformation and drying stress, Danvind and Synnergren reported (2001) that the deformation during drying can be understood using displacement detection because wood deformation during drying causes stress concentration and drying check. In the late 90 s, more accurate deformation measurement became possible as more advanced DIC systems were developed 
(Schmidt et al., 2002a, b).

We adopted this advanced technology in wood drying to understand the wood deformation mechanisms. We applied a DIC system for both fast-drying and typical refractory species, measured the three-dimensional strain distribution of the wood, and investigated the possibility of drying check detection using an optical measurement method. These efforts can reduce the cost and aid in the time optimization of the wood drying schedule, in addition to possibly elucidating the appropriate drying schedule for a refractory wood species.

\section{MATERIALS AND METHODS}

The experimental apparatus was established as shown in Fig. 1. The optical measurement system consisted of two lenses, a digital image capture board and a trigger. A lighting device was adopted so as to produce a bright and clear image.

Two different tree species were used; the fast-drying willow tree species was used for the three-dimensional deformation image, while the other, Oregon oak, a typical refractory wood, was used to observe check generation during wood drying. Wood sample specimens from 17-mm-thick and 8-mm-thick tree disks with 60-mm diameters were prepared from a freshly-cut willow tree. Willow specimens of $17-\mathrm{mm}$-thickness were used to compare the contour images of free and restrained deformations. A free deformation specimen was made by cutting it cone-shaped. Oak sample specimens with 70-mm widths, 80-mm lengths and 15-mm thicknesses were prepared from quarter sawn lumber in the longitudinal-tangential plane to ease drying check observation, as the drying check of oak usually originates in a region of ray tissue on the tangential plane. Subsequently, oak sample specimens were immersed into water prior to the experiment, because part of the sample specimen had already dried. All of the experiments were conducted at room temperature.

The side of the sample specimen that was turned toward the measuring lens was covered with black paint spots in order to atomize the sample surface. These spots unintentionally caused the formation of various grey scales that elevated the degree of correctness of the DIC

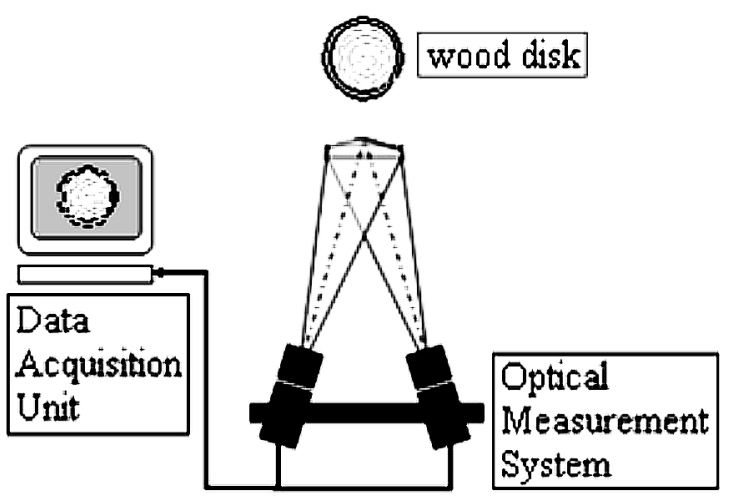

Fig. 1. Simplified diagram of the experimental apparatus, which consists of two cameras and a high-speed computer. system, which recognizes displacement according to subset movement. A DIC system can be reiterated and creates a subset composed of tens to hundreds of pixels in a single image. Displacement can be used to compare and calculate the locations of many subsets in a serial image. If the two subsets become close, then it shrink, swell if it becomes get away. Great care was needed to keep the specimens and camera stable, as any movement would negatively affect the image. The DIC system used in this research was VIC3D (USA Correlated Solutions Company).

\section{RESULTS AND DISCUSSION}

The DIC program materializes and enables the quantitative analysis of all of the elements of the local surface strain tensors and local displacement vectors. Furthermore, z represents the displacement between the lens and the sample specimen as a horizontal displacement change.

The contour maps in Fig. 2 show the deformation discrepancy between the disk and cone-shaped specimen looks uniform regardless of drying time. It implies that it shrank freely and is of less stress during drying. In contrast there are variable colors within the disk specimen. It shows that the core shrinks more than the outer, which develops drying stress within the specimen. This experiment confirmed that DIC method would be used to monitor the deformation of the specimen during drying. Furthermore, It could be reduced the possibility of crack or split caused by drying stress in tree disk by early adjustment of drying schedule.

Fig. 3 shows a displacement map of the willow disks according to drying time. The major displacement elements e1 and e2 closely agreed with each radial direction and tangential direction displacement.

Both strain maps of the radial and tangential directions showed that the pith region of the willow disk contracted faster than did the other regions. It is generally recognized that the contraction ratio in the tangential direction is greater than that in the radial direction. This tendency was also observed in this experiment (refer to Figure 3). In addition, the overall radial direction (e1) contraction surface was comparatively even over time, while that of the tangential direction (e2) was random. These observations could have not been made without the DIC system. Additionally, during drying, the willow disk is divided into several regions and shrinks or swells, and the dimension is illustrated in Fig. 3.

We compared the digital image of the Oregon oak sample specimen and the strain map of the displacement produced by the DIC system (Fig. 4). No check was found in the Digital Images after 9 and 12 hours, there were very minute drying check vestiges in the Digital Image at 15 hours, and the drying check looked very clear in the Digital Image at 42 hours. Conversely, the drying check seemed to take place in the first nine hours in the displacement map of the painted wood. Thus, we determined that the DIC system can detect drying checks due to drying stress more sensitively than can the digital 
image. As seen in the results shown in Fig. 4, this image system uses the color red to indicate expansion and the color blue to represent contraction. The contraction and expansion occurred simultaneously in the narrow areas. Therefore, the red color points and the blue color points

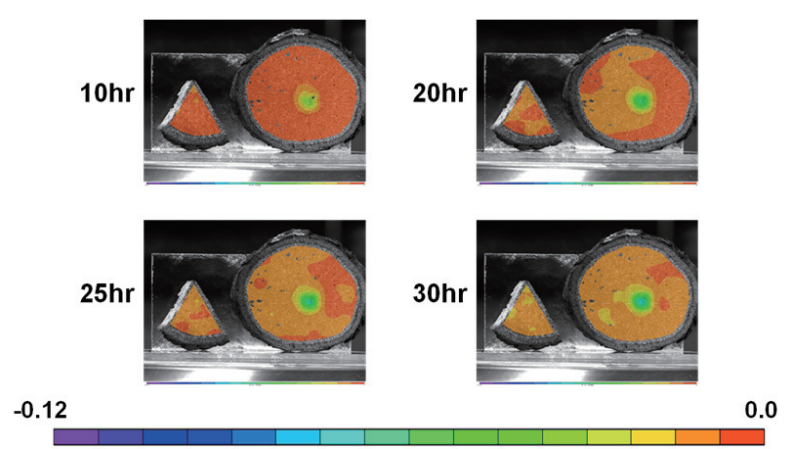

Fig. 2. Comparison of free and restrained strains of willow species tree disks prepared with $60-\mathrm{mm}$ in diameter and $17-\mathrm{mm}$ in thickness. The color bar at bottom is a deformation scale. A negative value represents the proportion of wood contraction.

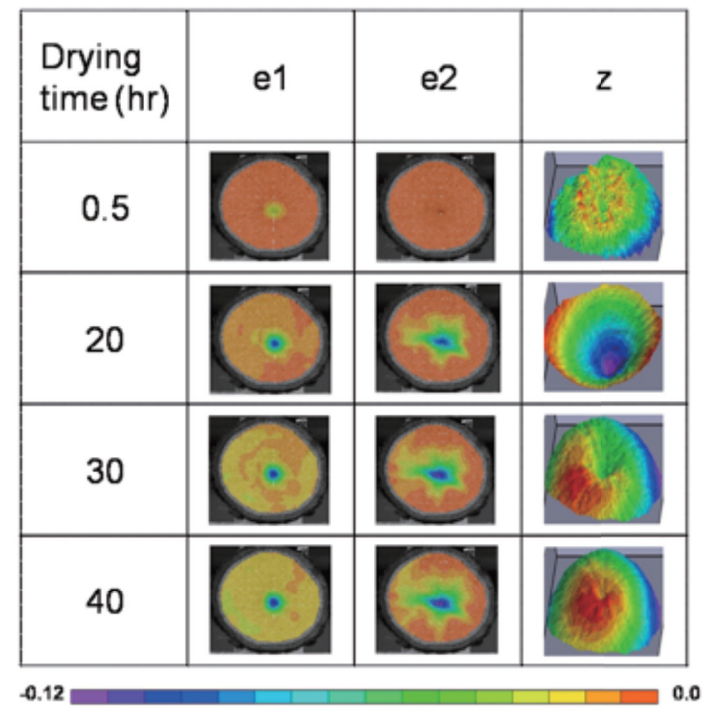

Fig. 3. The principal strain components e 1 and $\mathrm{e} 2$, and horizontal displacements, $z$, between the lenses and the sample at various drying times. e1 and e2 imply the strains in radial and tangential directions, respectively. The color bar at bottom is a deformation scale. A negative value represents the proportion of wood contraction.
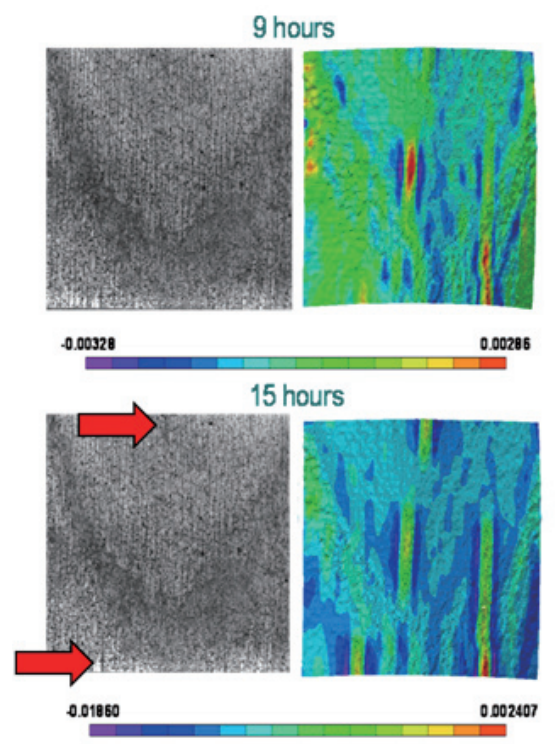
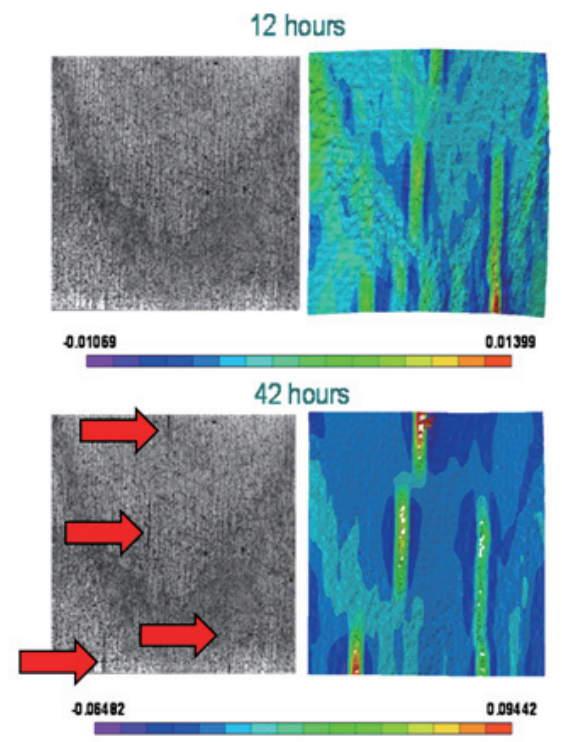

Fig. 4. The digital images and strain maps of an Oregon oak sample at various drying time. The color bar at bottom is a deformation scale. Negative and positive values represent the proportions of wood contraction and expansion, respectively.
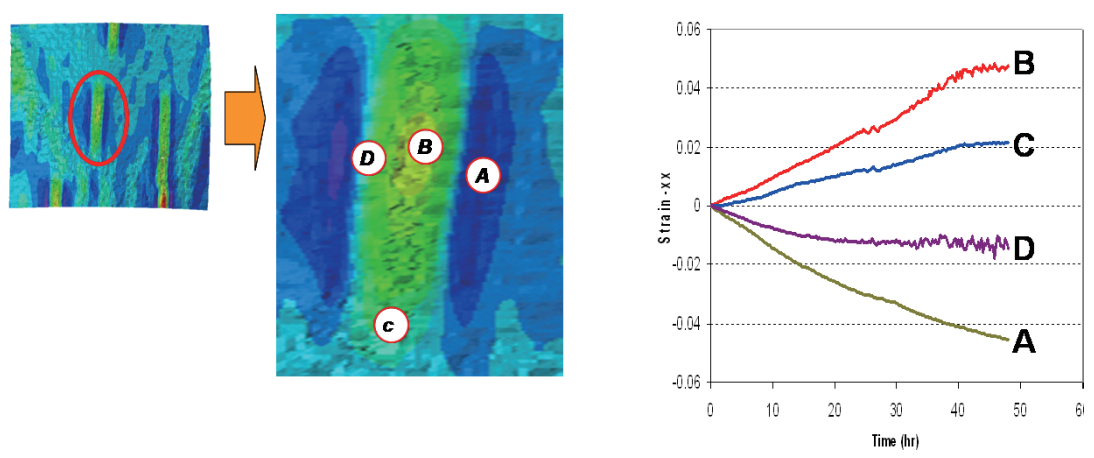

Fig. 5. The strains measured at four points around a checking developing during drying. 
received tension and compression stress, respectively.

A closer look at a checking in Fig. 5 illustrates its development during drying. The discrepancy of strains between the expansion and shrinking points increased with the drying time. Hence, we could acquired the accurate drying stress originated position and the degree of stress during drying.

From these results, we concluded that the use of a DIC system in wood drying can more accurately visualize strain changes and aid in the preparation of a more effective drying schedule for refractory wood species.

\section{CONCLUSIONS}

Using optical measurement techniques with a DIC (digital image correlation) system, we investigated the displacement changes in Willow tree disks and Oregon Oak planks, producing detailed displacement maps for the two species and the changes that occurred during drying. The stress concentration in the Oregon Oak plank was successfully visualized and the results are summarized as follows:

1. The radial direction contractions for all surfaces were comparatively even over time, while that in the tangential direction was random.

2. The DIC system could detect the drying check due to drying stress more sensitively than could the digital image.

3. Contraction and expansion during wood drying happened simultaneously in narrow areas.

From these results, we conclude that the use of a DIC system in wood drying can better visualize strain changes during wood drying and aid in the development of a more effective drying schedule.

However, the results obtained in this study deal with only surface deformation, and a more systematic study related to thickness variation should follow.

\section{ACKOWLEDGEMENT}

This study was supported by Technology Development Program of the Ministry of Agriculture and Forestry, Republic of Korea

\section{REFERENCES}

Breese, M. C., S. Zhao and G. McLeod 1995 The Use of Acoustic Emissions and Steaming to Reduce Checking During the Drying of European Oak. Holz als Roh-und Werkstoff, 53(6): 393-396

Bruck, H. A., S. R. McNeill, M. A. Sutton and W. H. I. Peters 1989 Digital Image Correlation Using Newton-Raphson Method of Partial Differential Correction. Experimental Mechanics, 28(3): 261-267

Carlsson, P. 2001 Distributed Optimization with a TwoDimensional Drying Model of a Board, Built up by Sapwood and Heartwood. Holzforschung, 55(4): 426-432

Choi, S. and S. P. Shah 1997 Measurement of Deformations on Concrete Subjected to Compression Using Image Correlation. Experimental Mechanics, 37(3): 307-313

Danvind, J and P. Synnergren 2001 Method for measuring contraction behaviour of drying wood using digital speckle pho- tography and X-ray computerised tomography. Proceedings of 7th IUFRO Wood Drying Conference. July 9-13, 2001, Tsukuba, Japan: 276-281

Kang, H.-Y. and N.-H. Lee 2002 Mathematical Modeling to Predict Drying Deformation and Stress Due to the Differential Contraction within a Tree Disk. Wood Science and Technology, $\mathbf{3 6}(6)$ : 463-476

Kim, K.-B., H.-Y. Kang, D. J. Yoon and M. Y. Choi 2005 Pattern Classification of Acoustic Emission Signals during Wood Drying by Principal Analysis and Artificial Neural Network. Key Engineering Materials, 297-300: 1962-1967

Krug, D., S. Tobisch, R. Emmler and K. Froehlich 1995 The Use of Certain Parameters of the Acoustic Emission Analysis for the Control of Wood Drying Processes. Holz als Roh-und Werkstoff, $\mathbf{5 3}(4)$ : 253-256

Lee, S. H., S. Quarles and A. P. Schniewind 1995 Wood Fracture, Acoustic Emission, and the Drying Process. Part 2. Acoustic Emission Associated with Fracture. Wood Science and Technology, 30: 283-292

Mott, L., S. M. Shaler and L. H. Groom 1996 A Novel Technique to Measure Strain Distributions in Single Wood Fibers. Wood and Fiber Science, 28(4): 429-437

Muszyński, L., R. Lagana and S. M. Shaler 2006 HygroMechanical Behavior of Red Spruce in Tension Parallel to the Grain. Wood and Fiber Sience, 38(1): 155-165

Ormarsson, S., O. Dahlblom and H. Petersson 1999 A Numerical Study of the Shape Stability of Sawn Timber to Moisture Variation. Part 2. Simulation of Drying Board. Wood Science and Technology, 33: 407-423

Pang, S., I. Simpson and T. Haslett 2001 Cooling and Steam Conditioning after High-Temperature Drying of Pinus Radiata Board: Experimental Investigation and Mathematical Modeling. Wood Science and Technology, 33(5): 487-502

Ranson, W. F., M. A. Sutton and W. H. Peters 1987 Holographic and Specle Interferometry. In "SEM Handbook of Experimental Mechanics”, ed. by A. S. Kobayashi, Englewood Cliffs, Prentice-Hall, Inc., pp. 388-429

Sakagami H., J. Matsumura and K. Oda. 2007 Shrinkage of tracheid cells with desorption visualized by confocal laser scanning microscopy. IAWA J., $\mathbf{2 8}(1)$ : 29-37

Sakagami H., J. Matsumura and K. Oda. 2009 Microcracks occurring during drying visualized by confocal laser scanning microscopy. IAWA J., $\mathbf{3 0}(2)$ : 179-187

Sakagami H., J. Matsumura and K. Oda. 2009 In-situ visualization of hardwood microcracks occurring during drying. $J$ of Wood Science, $\mathbf{5 5}(5)$ : 323-328

Schmidt, T., J. Tyson and K. Galanulis 2002a Full-Field Dynamic Displacement and Strain Measurement Using Advanced 3-D Image Correlation Photogrammetry. Part I. Experimental Techniques, $\mathbf{2 7}(3)$ : 47-50

Schmidt, T., J. Tyson and K. Galanulis 2002b Full-Field Dynamic Displacement and Strain Measurement Using Advanced 3-D Image Correlation Photogrammetry. Part II. Experimental Techniques, 27(4): 44-47

Sinha, A., R. Gupta and L. Muszyński 2006 Load Sharing between Gypsum Wall Board and Structural Wood Panel in Wood Frame Shear Walls. In "Proceedings of 9th World Conference on Timber Engineering" WCTE 2006, Portland, OR, August 6-10, 2006. p. 8

Sutton, M. A. and Y. J. Chao 1988 Measurement of Strains in a Paper Tensile Specimen Using Computer Vision and Digital Image Correlation. TAPPI Journal, 71(3): 173-175

Svensson, S. and A. Martensson 2002 Simulation of Drying Stresses in Wood: Part II Convective Air Drying of Sawn Timber. Holz als Roh-und Werkstoff, 60 (1): 72-80

Vendroux, G. and W. G. Knauss 1998 Submicron Deformation Field Measurements: Part 2. Improved Digital Image Correlation. Experimental Mechanics, 38(2): 86-92

Zink, A., R. Davidson and R. Hanna 1995 Strain Measurement in Wood Using a Digital Image Correlation Technique. Wood and Fiber Science, 27(4): 346-359 